\title{
IMPROVEMENT OF TOTAL EFFICIENCY OF HYDROSTATIC TRANSMISSION BY USING OPTIMIZED CONTROL
}

\author{
Mika IJAS and Esa MÄKINEN \\ Tampere University of Technology \\ Department of Intelligent Hydraulics and Automation \\ IHA - Rauma Research Unit \\ P.O.Box 236 \\ 26101 Rauma, Finland \\ Phone +358 2823 4970, Fax +35828234974 \\ E-mail:mika.ijas@tut.fi \\ E-mail: esa.makinen@tut.fi
}

\begin{abstract}
A basic hydrostatic transmission consists of a variable hydraulic pump and variable hydraulic motor. The most popular strategy is to control the units in sequence. From standstill up to a speed limit set by the maximum pump displacement, the output speed is controlled by the pump. Further increase of the output speed is achieved by decreasing the motor displacement. This way to control of HST is not best thinking of total efficiency. Efficiency of the hydraulic pump and the hydraulic motor are function of pressure, rotating speed and control angle. If it is possible to control independently the hydraulic motor and the hydraulic pump, it can be optimized total efficiency for every operating point (torque and rotating speed of the hydraulic motor). In this study control settings of the hydraulic pump and the hydraulic motor are optimized for each operating point so that the total efficiency should be as good as possible. These optimized efficiencies are compared to efficiencies from traditional control. The entire operating band was studied (rotating speed and torque of the motor) using simulation. Exactly verified simulation models of the HST were used. The base of simulation models was measured data from earlier studies. The results show that efficiency can be improved when the load is low. Power loss decreased maximum about $1.5 \mathrm{~kW}$.
\end{abstract}

\section{KEY WORDS}

Key words, Hydrostatic transmission, control, optimization 


\section{INTRODUCTION}

The closed circuit hydrostatic transmission generally comprises three components: a prime mover (for example electric motor), the hydraulic pump, which converts mechanical power into fluid power and the hydraulic motor, which converts fluid power back into mechanical power.

The ideal hydraulic pump and motor is defined as having efficiency of $100 \%$ with no power losses due to leakages or friction. This is no not possible in practice. Variables in hydrostatic transmission which significantly affect the behavior of a system are:

- The operation variables: the rotational speed of the pump, motor and prime mover and the pressure difference across the hydraulic pump and motor

- The hydraulic pump and motor parameters: the volumetric displacement and displacement setting of a unit

- Fluid parameters: the dynamic viscosity, density and effective bulk modulus.

The traditional control of HST (pump and motor) operates as follows: The volumetric displacement of the hydraulic pump is first increased from zero to 1 (the volumetric displacement of the hydraulic motor is at value one). If there is a need to increase the speed of the hydraulic motor, the volumetric displacement of the motor has to be reduced from one to its minimum value (in this study to $1 / 3$ from maximum value).

The total efficiency of the whole system is not very high. The low efficiency of the hydraulic pump and motor increases the temperature of the hydraulic oil. The oil reservoir is typically quite small and it is quite difficult to cool the oil especially in the summer time. The efficiency of the hydraulic components is varying a lot in the HST so the total efficiency is a function of many parameter and variable.

\section{SIMULATION MODEL OF HST [1], [2]}

Several different steady-state loss models for hydraulic pumps and motors can be found in the literature. One category of such models (the most common ones) is coefficient models. In most cases the coefficients can be defined by the data given by manufacturer. Another group of loss models is based on measurement. In these models the losses of hydraulic pump and motor are described on the basis of measured data.

The simulation model of efficiency bases on two-line principle in this work. Instead of modeling different loss sources, the two-line principle is based on describing the change in losses as a function of the system variables such as pressure, displacement and rotational speed. The loss model is based on measured data of hydraulic unit. With these measurements two curves are obtained by using polynomial fitting according to two lines [1]. All models have been evaluated and tested in the fluid power laboratory at Tampere University of Technology [1], [2], [3].

The model of hydraulic pump and hydraulic motor used take into consideration also the power loss of the boost pump and minor losses of hydraulic lines. The variables in the simulation model of the hydraulic pump are the following: the pressure difference over the pump, the rotational speed and the displacement control of the pump. The constants are the volumetric displacement, the lowest and highest pressure and the lowest and highest speed of the hydraulic pump. Maximum ratings are needed for the calculation of efficiency. With these parameters the capacity, torque and efficiency of the pump are calculated with the help of the two-line principle. The functions are fitted into the measured data.

The inputs of the model are rotational speed, displacement setting, displacement and working pressure. The outputs of the model are load torque to the prime mover, volumetric flow and total efficiency of the hydraulic pump. These output signals can be connected as inputs to the other blocks of the simulation model of the hydrostatic transmission system. The hydraulic motor is modeled with the same principle as the hydraulic pump. The model used in this study includes submodels for the feed pump, pressure relief valve and hydraulic pipes.

Figure 1 show a simulated example of total efficiency of HST when the size of the pump was $125 \mathrm{~cm}^{3}$ and the nominal size of the motor was $160 \mathrm{~cm}^{3}$. The system is protected against overloads by pressure relief valves. Therefore there is a huge dropping of efficiency in area of high torque and high rotating speed. The total efficiency of the HST is not very high at the starting point. The reason for this is the poor efficiency of the motor at low running speeds. The efficiency increases rapidly and the maximum point is achieved just after the control has been changed from the pump to the motor. After that the efficiency reduces, when the running speed of the motor increases. 


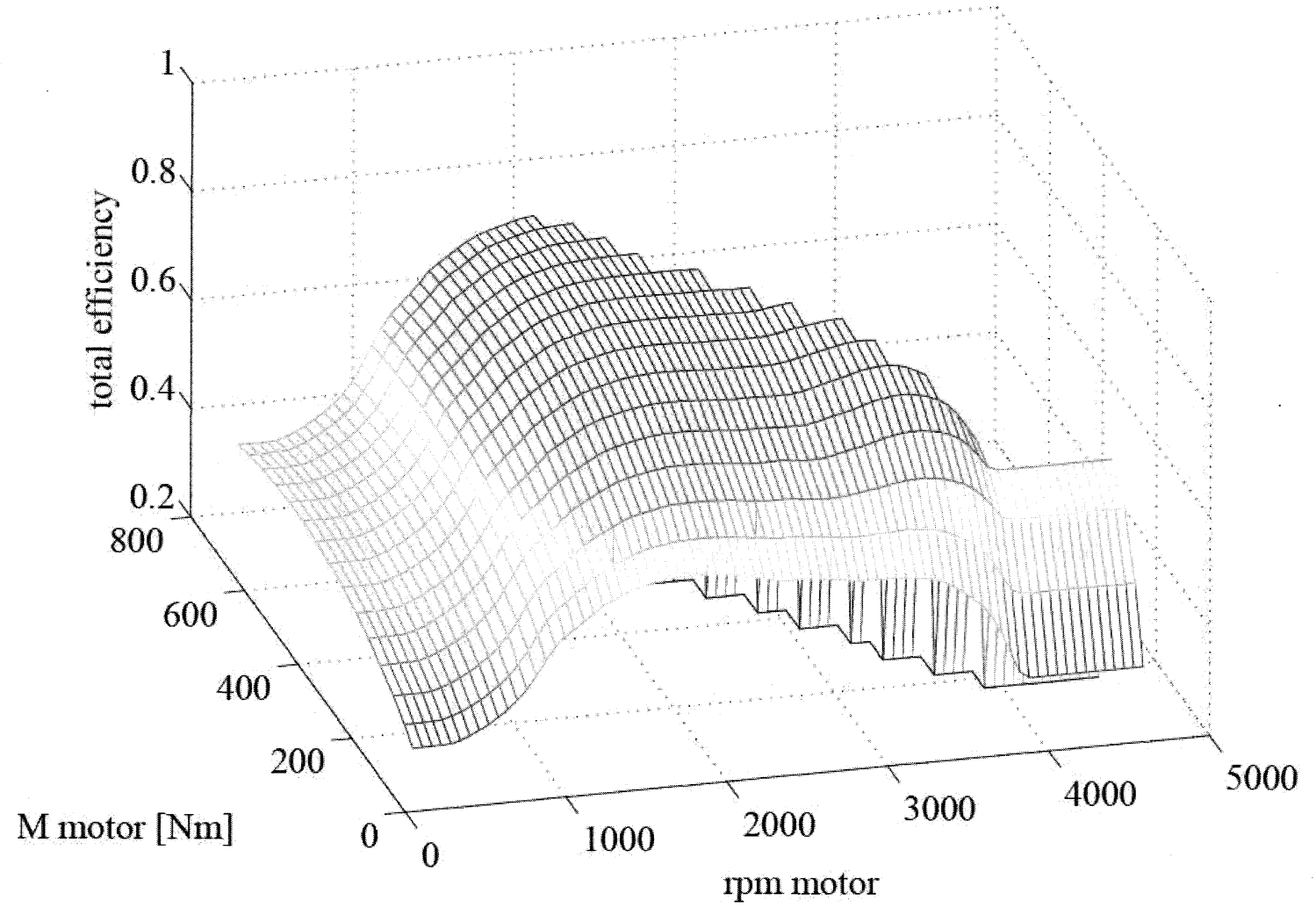

Figure 1. Total efficiency of HST.

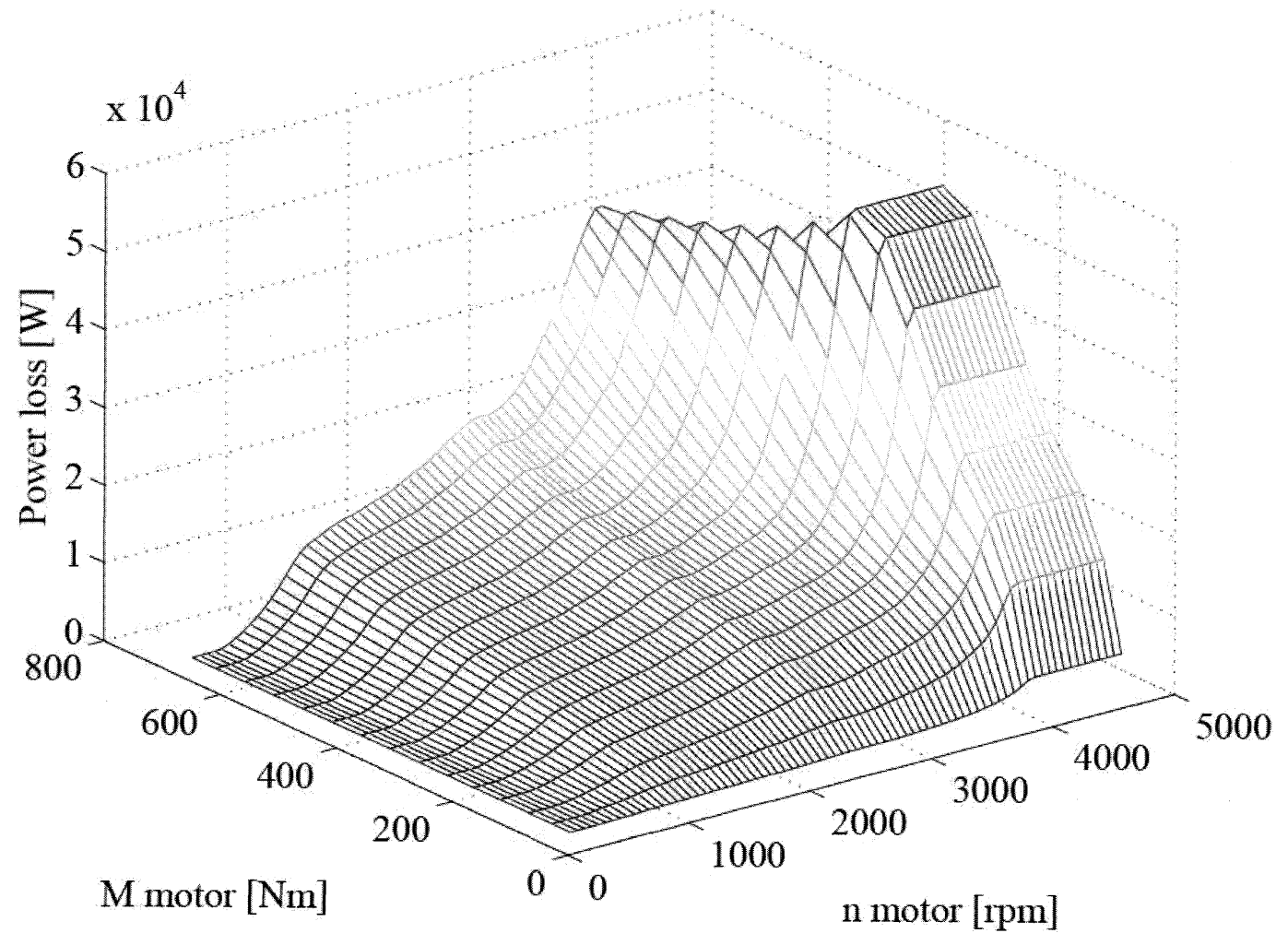

Figure 2. Power loss of HST. 
However, the total efficiency is low when the rotating speed and torque are low. Total efficiency is maximum $90 \%$ but decrease rapidly when the operational point goes to an edge area. The best efficiency is when the rotating speed is about $1 / 3$ of maximum and torque is about $1 / 2$ of maximum.

Figure 2 shows simulated power loss of HST when sizes of components were same as in Figure 1. Even if the total efficiency is poor in low rotating speed, the power loss isn't high because the power level is also low. When the power level is high (high rotating speed and high torque) the total efficiency is quite good.

\section{OPTIMIZED HST CONTROL}

The main idea of optimized control is that the best settings values of pump and motor control is founded for every operation point. The total efficiency becomes as good as possible. There is not this kind of controller system on the market but the optimization has been made "manually" in this study.

In the figure 3 rotating speed was $10001 / \mathrm{min}$ and the torque of the motor was $100 \mathrm{Nm}$. The size of the pump was $125 \mathrm{~cm}^{3}$ and size of the motor was $160 \mathrm{~cm}^{3}$.

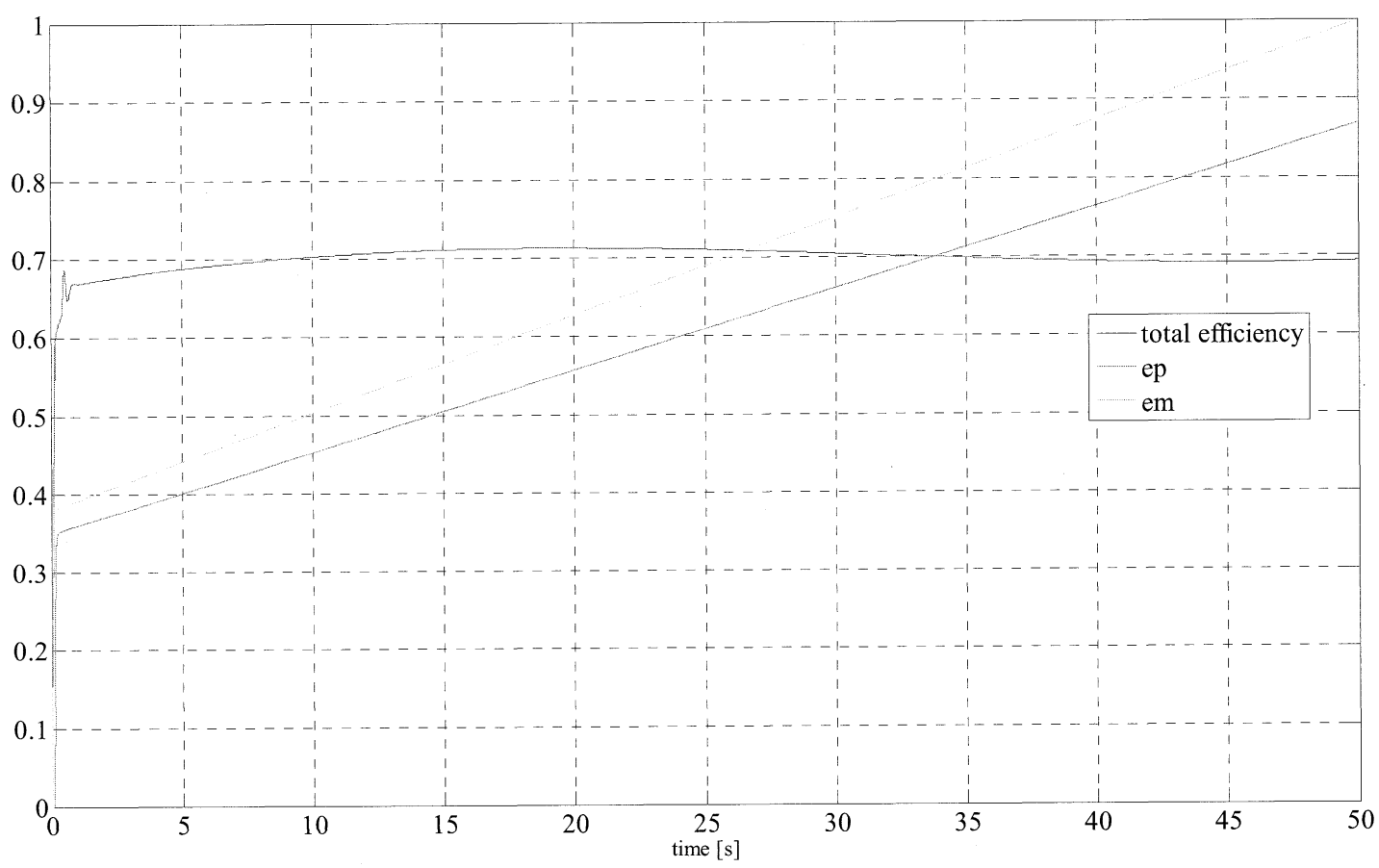

Figure 3. Total efficiency and control angles of HST during simulation. 


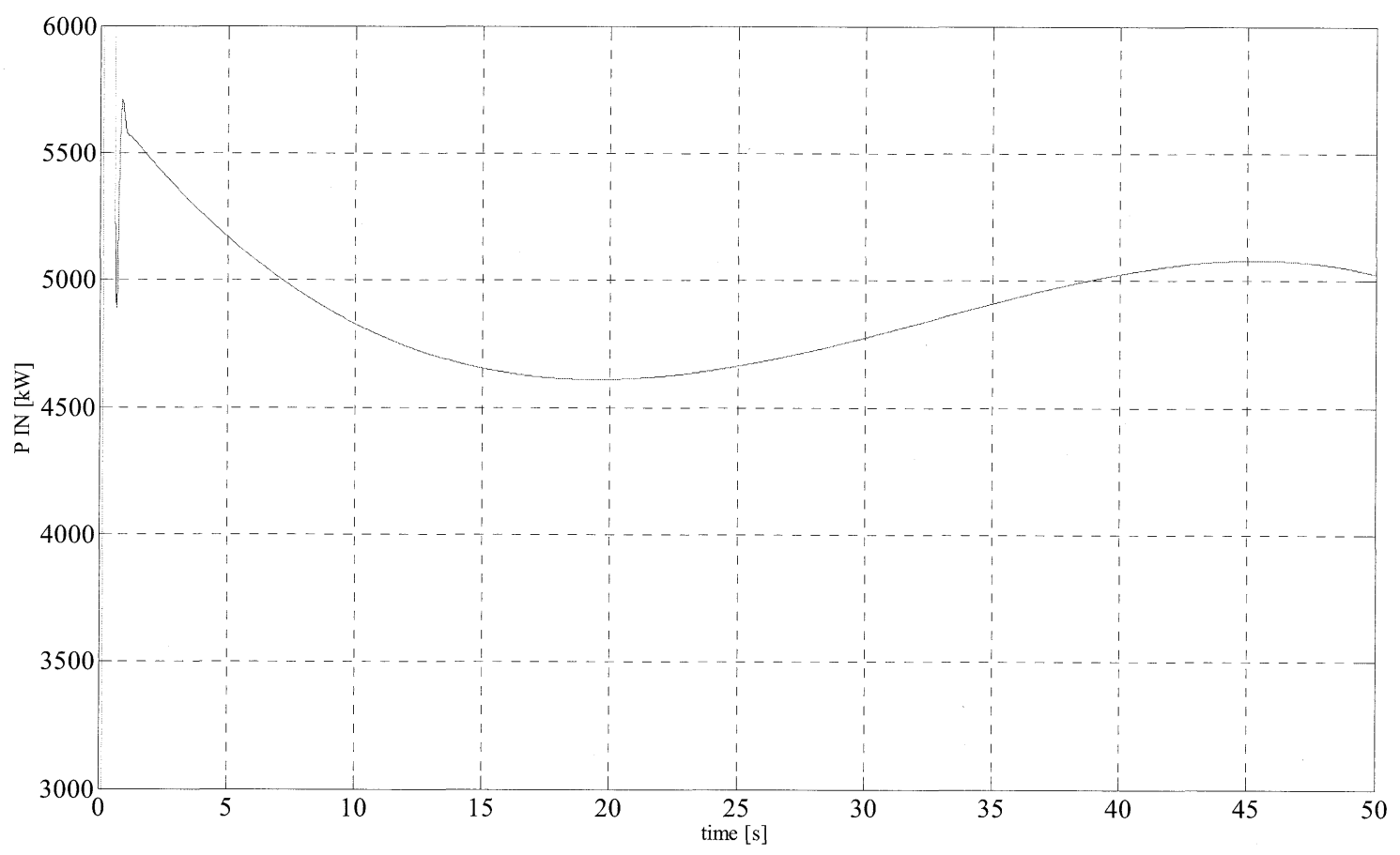

Figure 4. INPUT power of HST during simulation.

The best efficiency is at time 20,8s when input power of HST is $4635 \mathrm{~W}$ (Figure 4). In the traditional control of HST pump setting 0,87 and motor setting 1,00 result in $1000 \mathrm{l} / \mathrm{min}$ rotating speed but the INPUT power of HST was $5118 \mathrm{~W}$. In this case the save was $483 \mathrm{~W}$ when using the optimized control.

This study is done manually step by step. Every operation point (rotating speed and torque of hydraulic motor) needs one simulation as earlier was depicted. This needs a numerous simulations that sufficient cover of operation points were reached.

Figure 5 shows achievable improvements of power save. If the improvement is 0 it refers that traditional control of HST operates on its best efficiency.

The optimized control causes highest improvements when the load is low $(<500 \mathrm{Nm})$. The best improvement is about $1.5 \mathrm{~kW}$, when rotating speed is $10001 / \mathrm{min}$ and torque $100 \mathrm{Nm}$. If the torque is high $(>500 \mathrm{Nm})$ the traditional control of HST operates at its best way. 


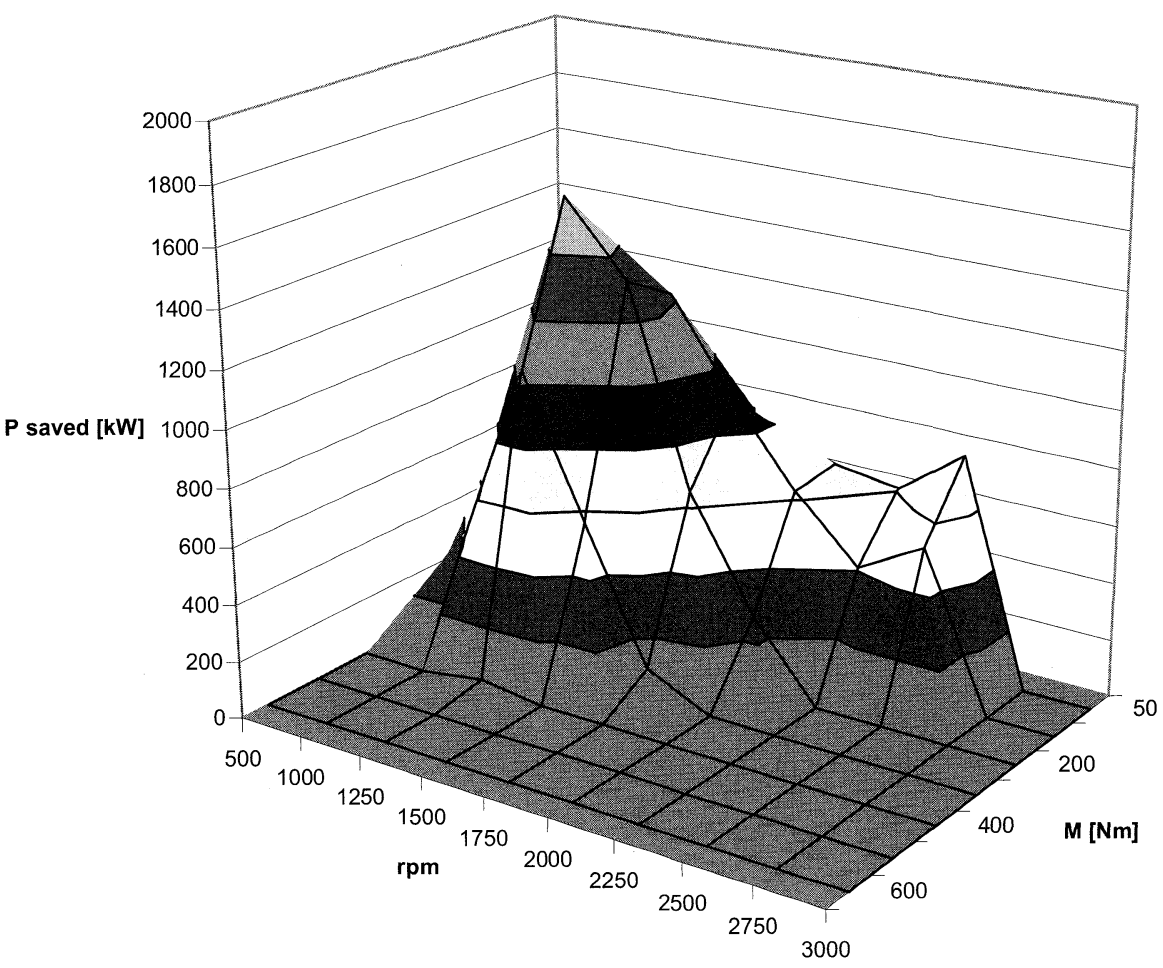

Figure 5. Simulated achievable improvements of power save of HST.

\section{CONCLUSIONS AND DISCUSSION}

According to this study the best improvements of power save was about $1.5 \mathrm{~kW}$ HST size like this. The best accessible improvements are at low torques. If the operating point is continuously at bad operating point area, $1.5 \mathrm{~kW}$ saving would affect to rising time of temperature notably. However, the traditional control operates well on most operating points. Advantages of optimized control disappear if the operating point varies much. Optimized control is more complex compared to traditional control because it needs separate control system to the hydraulic pump and to the hydraulic motor. It needs also the high level control, which optimizes total efficiency continuously. In this time there is not this kind of control system on the market.

The optimized control improves to total efficiency of the HST but there are also other ways to improve the efficiency balance. For example smart control, which stops prime mover when HST idling, saves energy much. Long idle running of HST is avoidable operation. Power lost of idling HST is about $5 \mathrm{~kW}$.

The other case to save power is reducing a flushing loss of HST. There is continues flushing flow through flushing valves which decreases the total efficiency of
HST. It should be study can power level decreases by reducing flushing pressure level in some circumstances.

\section{REFERENCES}

1. Huhtala, K. 1996. Modelling of Hydrostatic Transmission- Steady State, Linear and Non- Linear Models, Acta Polytychina Scandinavica Me 123, dissertation

2. Fonselius, J. 2001. Comparing Different Control Strategies of Hydrostatic Transmission System. Acta Polytychina Scandinavica Me 151, dissertation

3. Erkkilä. M. 2007. Dynamic Model of CVT Power Train. The Tenth Scandinavian International Conference on Fluid Power, SICFP'07, May 21-23, Tampere Finland 